\title{
Evaluation of the dermatomal somatosensory evoked potential in the diagnosis of lumbo-sacral root compression
}

\author{
H A KATIFI, E M SEDGWICK \\ From the Wessex Neurological Centre, General Hospital, Southampton, UK
}

SUMMARY The dermatomal somatosensory evoked potential from the lumbo-sacral dermatomes was recorded from 21 patients with radiographically and surgically (20) proven lumbo-sacral root compression due to prolapsed intervertebral disc or canal stenosis. The potential was abnormal in 19 of the 20 surgically proven cases. The dermatomal somatosensory evoked potential is as accurate as myelography for diagnosis but has the advantage of being non-invasive and repeatable. It provides useful additional diagnostic and pathophysiological information about lumbo-sacral root compression.

Diagnosis of lumbo-sacral root compression would be aided by a reliable test of conduction through the sensory nerve root, as compressed nerves have reduced conduction velocities. Electromyographic investigation of root disorders relies on the $F$ response which tests only the motor root, the $\mathrm{H}$ reflex which depends on both motor and sensory roots, and the use of concentric needle myography to detect denervation in muscles, which also evaluates only the motor root. These methods have a low diagnostic yield ${ }^{1}$ although considerable success has been claimed in selected patients. ${ }^{2}$ Patients present most commonly with only sensory symptoms and signs yet there is no objective way of testing sensory roots.

A method for stimulating individual dermatomes and recording the somatosensory evoked potential from the scalp has been described. ${ }^{3}$ Preliminary results indicate that a delayed or absent dermatomal somatosensory evoked potential may be diagnostically useful. ${ }^{4}$ One criticism of the technique is that stimulation of the skin must excite nerve fibres traversing two or three roots owing to the overlap of segmental innervation. To overcome this we stimulated the "signature" areas of the dermatomes where

Address for reprint requests: Dr E M Sedgwick, Wessex Neurological Centre, Southampton General Hospital, Shirley, Southampton SO9 4XY, UK.

Received 29 July 1986 and in revised form 7 January 1987. Accepted 19 January 1987 sensory loss first occurs and is most dense. ${ }^{56}$ It was assumed that overlap at these sites would be minimale and preliminary results of direct recording support this. ${ }^{7}$

This paper describes the application of the technique to patients with clinically definite root lesions confirmed radiologically and surgically. The cause of compression was either prolapsed intervertebral discs or degenerative spondylotic spine disease causing canal stenosis. The study was designed as an evaluation of the sensitivity and accuracy of the dermatomal somatosensory evoked potential (DSEP) in proven cases as a basis for testing in cases where the diagnosis is in doubt. The findings show the technique to be as sensitive as myelography and to allow repeatable assessment of sensory root function.

\section{Methods}

Twenty one patients with back pain and sciatica were admitted under the care of neurosurgeons at this centre. Their clinical details are given in table 1 . The diagnosis was made from the clinical and myelographic examination and confirmed or modified by the operative findings. Surgeons were asked to identify at surgery which roots were compressed without prior knowledge of the dermatomal somatosensory evoked potential findings. The dermatomal somatosensory evoked potential was recorded prior to surgery but the results were not used to make the diagnosis or to determine the management.

The method for recording the dermatomal somatosensory evoked potential and the criteria for abnormality of the L5 and $\mathrm{S} 1$ dermatomes have been published. ${ }^{3}$ The findings were extended to other lumbar dermatomes to define abnormal- 
Table 1 Clinical signs, myelography, DSEP and operative findings

Clinical findings

\begin{tabular}{|c|c|c|c|c|c|c|c|c|c|c|c|}
\hline \multirow[b]{2}{*}{ iase } & \multirow{2}{*}{$\begin{array}{l}\text { Age } \\
(y r) \\
\& \operatorname{sex}\end{array}$} & \multirow{2}{*}{$\begin{array}{l}\text { Sciatica } \\
\text { Side \& } \\
\text { duration }\end{array}$} & & & $\begin{array}{l}\text { Tendon } \\
\text { knee, } \\
\text { ankle }\end{array}$ & eflex & $\begin{array}{l}\text { SLR \& } \\
\text { stretch }\end{array}$ & & \multirow[b]{2}{*}{ Myelography } & \multirow[b]{2}{*}{$D S E P$} & \multirow[b]{2}{*}{ Operative findings } \\
\hline & & & Motor & Sensory & $R t$ & $L t$ & $\overline{R t}$ & $\overline{L t}$ & & & \\
\hline 1 & $35 \mathrm{~F}$ & Lt $5 \mathrm{yr}$ & $\mathbf{N}$ & Lt S1 & $\begin{array}{l}++ \\
++\end{array}$ & $\begin{array}{l}++ \\
++\end{array}$ & 25 & 5 & L5/S1 PID & Lt L5 delay & $\begin{array}{l}\text { Central L5/S1 PID } \\
\text { compressing Lt L5 }\end{array}$ \\
\hline 2 & $69 \mathrm{M}$ & Lt $2 \mathrm{~m}$ & Lt L5, SI & Lt L5-S2 & $\begin{array}{l}++ \\
0\end{array}$ & $\begin{array}{l}++ \\
0\end{array}$ & 90 & 90 & $\begin{array}{l}\text { Large central } \\
\text { L4/5 PID }\end{array}$ & Rt L5, S1 absent & $\begin{array}{l}\text { LA/5 PID bilat L5 \& S1 } \\
\text { root compression }\end{array}$ \\
\hline 3 & $22 \mathrm{M}$ & Lt $2 \mathrm{yr}$ & $\mathbf{N}$ & $\mathbf{N}$ & $\begin{array}{l}++ \\
++\end{array}$ & $\begin{array}{l}++ \\
++\end{array}$ & 80 & $30+$ & $\begin{array}{l}\text { Left lateral } \\
\text { L4/5 PID }\end{array}$ & Normal & $\begin{array}{l}\text { L4/5 PID compressing L5 } \\
\text { root on } \mathrm{Lt}\end{array}$ \\
\hline 4 & $69 \mathrm{~F}$ & Lt $1 \mathrm{~m}$ & Lt L2-L5 & Lt L4, 5, S1 & $\begin{array}{l}++ \\
++\end{array}$ & $0^{++}$ & 80 & $50+$ & $\begin{array}{l}\text { Large central } \\
\text { L3/4 PID }\end{array}$ & $\begin{array}{l}\text { Delay Lt L4 } \\
\text { Absent Lt L5 }\end{array}$ & Conservative management \\
\hline-5 & $33 \mathbf{M}$ & Lt $6 \mathrm{~m}$ & Lt L5 & Lt L5 & $0^{++}$ & $0^{++}$ & 90 & 90 & Large central L4/5 & $\begin{array}{l}\text { Delay L5 } \\
\text { bilateral }\end{array}$ & $\begin{array}{l}\text { Central L4/5 PID and } \\
\text { postero-lateral L5/SI Rt L5 } \\
\text { root compressed }\end{array}$ \\
\hline 6 & $50 \mathrm{M}$ & $\mathbf{R t}>$ Lt 3 yr & Lt L5, S1 & Lt L4, 5, S1 & + & $0^{++}$ & 90 & 90 & $\begin{array}{l}\text { L4/5 PID complete } \\
\text { block CT-L4/5 PID }\end{array}$ & $\begin{array}{l}\text { Rt L5, S1 } \\
\text { Delayed }\end{array}$ & $\begin{array}{l}\text { Large L4/5 PID compressing } \\
\text { L5 bilat and Rt S1 }\end{array}$ \\
\hline 7 & $46 M$ & Rt 3 m & Rt L5, S1 & Rt S1 & ${ }_{0}^{++}$ & $\begin{array}{l}++ \\
++\end{array}$ & $10+$ & 90 & $\begin{array}{l}\text { Rt lateral L5/S1 } \\
\text { PID }\end{array}$ & $\begin{array}{l}\text { Rt \& Lt L5 delay } \\
\text { Rt SI delay }\end{array}$ & $\begin{array}{l}\text { L5/S1 PID compressing the Rt } \\
\text { L5 \& S1 the latter more } \\
\text { severely affected }\end{array}$ \\
\hline 8 & $42 \mathrm{~F}$ & Rt $1.5 \mathrm{yr}$ & $\mathbf{N}$ & $\mathbf{N}$ & $\begin{array}{l}++ \\
++\end{array}$ & $\begin{array}{l}++ \\
++\end{array}$ & 40 & 80 & $\begin{array}{l}\text { Central L2/3 PID } \\
\text { CT confirmed }\end{array}$ & $\begin{array}{l}\text { Bilat } L 4 \text { delay }>\text { on } \\
\text { the } R t . L 3 \text { normal }\end{array}$ & $\begin{array}{l}\text { L2/3 central PID affecting } \\
\text { L3 L4 nerve roots on the right }\end{array}$ \\
\hline 9 & $45 \mathrm{M}$ & Rt 1 yr & Rt L5 & $\mathbf{N}$ & $\begin{array}{l}++ \\
+\end{array}$ & $\begin{array}{l}++ \\
++\end{array}$ & 90 & 90 & Central L4/5 PID & Rt L5, S1 absent & L4/5 PID compressing Rt L5 \\
\hline 10 & $41 \mathrm{~F}$ & Rt \& Lt 4 yr & Bilat L5 & Bilat S2-S4 & $\begin{array}{l}++ \\
++\end{array}$ & $\begin{array}{l}++ \\
++\end{array}$ & $10+$ & $10+$ & $\begin{array}{l}\text { Rt lateral L5/S1 PID } \\
\text { CT central L5/S1 PID }\end{array}$ & Lt L5 delay & $\begin{array}{l}\text { L5/S1 lateral PID } \\
\text { compressing Rt S1 }\end{array}$ \\
\hline 11 & $34 \mathrm{M}$ & Rt 1 yr & $\mathbf{N}$ & Rt L5, S1 & $\begin{array}{l}++ \\
++\end{array}$ & $\begin{array}{l}++ \\
++\end{array}$ & $40+$ & 90 & Central L5/S1 PID & Rt L5 absent & $\begin{array}{l}\text { Large L5/S1 PID compressing } \\
\text { Rt L5 root }\end{array}$ \\
\hline 12 & $58 \mathrm{M}$ & $\mathrm{Lt}>\mathrm{Rt} 1 \mathrm{yr}$ & $\mathbf{N}$ & Lt L4-S1 & $\begin{array}{l}++ \\
++\end{array}$ & $\begin{array}{l}++ \\
+\end{array}$ & 90 & 90 & $\begin{array}{l}\text { Central L3/4 \& } \\
\mathrm{L} 4 / 5\end{array}$ & $\begin{array}{l}\text { Bilat L5 delay } \\
\text { Lt S1 delay }\end{array}$ & $\begin{array}{l}\text { Central L3/4 PID L4/5 canal } \\
\text { stenosis involving the L5 } \\
\text { roots bilaterally }\end{array}$ \\
\hline $\begin{array}{l}13 \\
-\end{array}$ & $64 \mathrm{~F}$ & Rt 2 yr & $\mathbf{N}$ & $\mathbf{N}$ & $\begin{array}{l}++ \\
++\end{array}$ & $\begin{array}{l}++ \\
++\end{array}$ & 75 & 90 & $\begin{array}{l}\mathrm{L} 2 / 3, \mathrm{L3} / 4 \\
\text { impressions } \mathrm{L} 4 / 5 \\
\text { spondylolithesis }\end{array}$ & $\begin{array}{l}\text { Bilat L4, } 5 \\
\text { delay Lt S1 delay }\end{array}$ & $\begin{array}{l}\text { Lumbar canal stenosis } \mathrm{L} 4 / 5 \text { \& } \\
\text { L5/S1 L4 \& L5 roots involved } \\
\text { bilaterally }\end{array}$ \\
\hline 14 & $62 \mathrm{~F}$ & Lt $9 \mathrm{~m}$ & Lt L5 & $\mathbf{N}$ & $\begin{array}{l}++ \\
++\end{array}$ & $\begin{array}{l}++ \\
++\end{array}$ & 90 & +60 & $\begin{array}{l}\text { Lt lateral L4/5 } \\
\text { PID }\end{array}$ & Lt LS delay & $\begin{array}{l}\text { L4/5 spondylosis compressing } \\
\text { the Lt L5 root. No PID }\end{array}$ \\
\hline 15 & $46 \mathrm{~F}$ & Lt $4 \mathrm{~m}$ & Lt L5 & $\begin{array}{l}\text { Lt } \mathbf{L S} / \mathrm{S} 1 \\
+ \text { perianal }\end{array}$ & $\begin{array}{l}++ \\
++\end{array}$ & $\stackrel{+}{0}$ & 70 & $35+$ & $\begin{array}{l}\text { Lt lateral L4/5 } \\
\text { PID }\end{array}$ & $\begin{array}{l}\text { Lt L5 S1 } \\
\text { absent }\end{array}$ & $\begin{array}{l}\text { Canal stenosis } \\
\text { Lt L5 compressed }\end{array}$ \\
\hline 16 & $44 \mathrm{M}$ & $\begin{array}{l}\text { Bilat Rt > } \\
\text { Lt } 4 \mathrm{yr}\end{array}$ & $\begin{array}{l}\text { L2-S1 } \\
\mathbf{L t}>\mathbf{R t}\end{array}$ & $\begin{array}{l}\text { Rt L4 } \\
\text { Bilat L5-S4 }\end{array}$ & $\begin{array}{l}+++ \\
+++\end{array}$ & $\begin{array}{l}+++ \\
+++\end{array}$ & $60+$ & 60 & $\begin{array}{l}\text { Spinal stenosis } \\
\text { complete } \mathrm{L} 1 / 2 \text { block }\end{array}$ & Rt L5 delay & Canal stenosis \\
\hline 17 & $67 \mathrm{M}$ & Lt 1 yr & Lt L3-5 & Lt L5 & $\begin{array}{l}++ \\
++\end{array}$ & $\begin{array}{l}+ \\
+\end{array}$ & 90 & $50+$ & $\begin{array}{l}\text { Spondylotic change } \\
\text { at } \mathrm{LS}, \mathrm{Lt} \mathrm{LS}, \mathrm{S1} \\
\text { roots obliterated }\end{array}$ & L5, S1 bilat & $\begin{array}{l}\text { Canal stenosis at } L 4 / 5, \mathrm{LS} / \mathrm{S} 1 \\
\text { compressing the } \mathrm{Lt} \mathrm{L} 5 \text { and } \\
\text { S1 N roots }\end{array}$ \\
\hline 18 & $51 \mathrm{M}$ & Lt $6 \mathrm{~m}$ & Lt L3 & L3, 4 & $\begin{array}{l}++ \\
++\end{array}$ & $\begin{array}{l}0 \\
++\end{array}$ & 90 & 75 & $\begin{array}{l}\text { Lt lateral L3/4 PID } \\
\text { and small L4/5 PID }\end{array}$ & $\begin{array}{l}\text { Lt L4 delay } \\
\text { Lt L3 absent }\end{array}$ & $\begin{array}{l}\text { Canal stenosis } \mathrm{L} 3 / 4 \text { mainly } \\
\text { on the left compressing the } \mathrm{Lt} \\
\text { L3 \& LA N root. No PID }\end{array}$ \\
\hline 19 & $61 \mathrm{~F}$ & Lt $>$ Rt $2 \mathrm{~m}$ & $\mathbf{N}$ & Lt L2-L4 & $\begin{array}{l}++ \\
++\end{array}$ & $\begin{array}{l}++ \\
+\end{array}$ & $40+$ & $50+$ & $\begin{array}{l}\text { LA/5 PID, facet } \\
\text { hypertrophy } \\
\text { complete obstruction }\end{array}$ & Rt LS, S1 delay & $\begin{array}{l}\text { Canal stenosis } \mathrm{L} 4 / 5, \mathrm{~L} / \mathrm{S} \text { I } \\
\text { LA \& } 5 \text { root involved } \\
\text { bilaterally }\end{array}$ \\
\hline 20 & $23 \mathrm{M}$ & Lt 2 yr & Lt LS & Lt S1 & $\begin{array}{l}++ \\
++\end{array}$ & $\begin{array}{l}++ \\
0\end{array}$ & 30 & +20 & $\begin{array}{l}\text { ? Lt S1 root fills } \\
\text { poorly. CT L5/S1 PID }\end{array}$ & Lt L5 delay & $\begin{array}{l}\text { Lt L5 root compressed by } \\
\text { fibrous tissue. No PID }\end{array}$ \\
\hline 21 & $36 \mathrm{M}$ & Rt 2 yr & $\mathbf{N}$ & $\mathbf{N}$ & $\begin{array}{l}++ \\
++\end{array}$ & $\begin{array}{l}++ \\
++\end{array}$ & 80 & 70 & $\begin{array}{l}\text { Normal. CT lateral } \\
\text { L5/SI PID }\end{array}$ & Normal & $\begin{array}{l}\text { Rt L5 root thick and } \\
\text { inflamed. No PID }\end{array}$ \\
\hline
\end{tabular}

Cases 2, 8, 10, 15 minor urinary symptoms (frequency, urgency). Case 12 urinary incontinence. 16 urinary retention and faecal incontinence.

Reflex: +++ brisk; + + normal; + reduced; 0 absent.

$\mathrm{N}=$ normal. Stretch test $+=$ Positive Lasegue. DSEP $=$ Dermatomal somatosensory evoked potential

PID = prolapsed intervertebral disc.

ities as follows:

(1) An absent DSEP.

(2) A side to side difference of more than $3.5 \mathrm{~ms}$ for L4.

(3) The latency of a dermatome should lie between the latencies of the dermatome above and the one below.

(4) Side to side amplitude ratio exceeding $4 / 1$.

(5) Latencies of response other than L5 and S1 taken from reference 8

Although a previous study showed no significant effect of age, allowance was made for this in patients over 45 years old whose absolute latency values were borderline. (See table
III in ref 3 ); latency is prolonged by approximately $0.86 \mathrm{~ms}$ per decade for L5 and 0.38 for S1.

Sensory threshold to stimulation of the skin by single pulses was determined by the method of limits and expressed in $\mathrm{mA}$. Pulses of $2.5 \times$ sensory threshold, which excite only cutaneous afferents, were used to evoke the potential. The stimulus was applied at the signature areas shown in fig 1 . The posterior tibial nerve was also stimulated at the ankle as previously described. ${ }^{3}$ Recording was from scalp electrodes placed at $\mathrm{Cz}^{\prime}$ ( $2 \mathrm{~cm}$ posterior to $\mathrm{Cz}$ on the 10-20 system) with the reference midway between $\mathrm{Fpz}$ and $\mathrm{Fz}$. The averaged 
waveform was a $\mathrm{W}$ shaped response and the latency to the first positive peak was measured. Responses were noted as delayed or absent and the findings were compared with the final diagnosis, (fig 2).

\section{Results}

Twenty one patients were studied; 13 were male and eight female. Their ages ranged from 22 to 69 years, mean 47.5 years and their symptoms had been present for 1 month to 5 years with a mean of 18.4 months.

The clinical details are shown in table 1; the final diagnosis was provided by the operative findings. Eleven had prolapsed intervertebral disc, including one whose condition improved and in whom surgery was deferred. Eight had spondylotic changes causing canal stenosis, this term is taken to include central canal, root canal and lateral recess stenosis. ${ }^{9}$ One of the eight patients had a prolapsed intervertebral disc also (case 12) but his problems related to the level of stenosis rather than to the disc. Of the two remaining patients, one had a L5 root compression by fibrous tissue but no disc or degenerative change. In the other, the root was described as thickened and inflamed but no disc or stenosis was seen.

Comparison of the dermatomal somatosensory

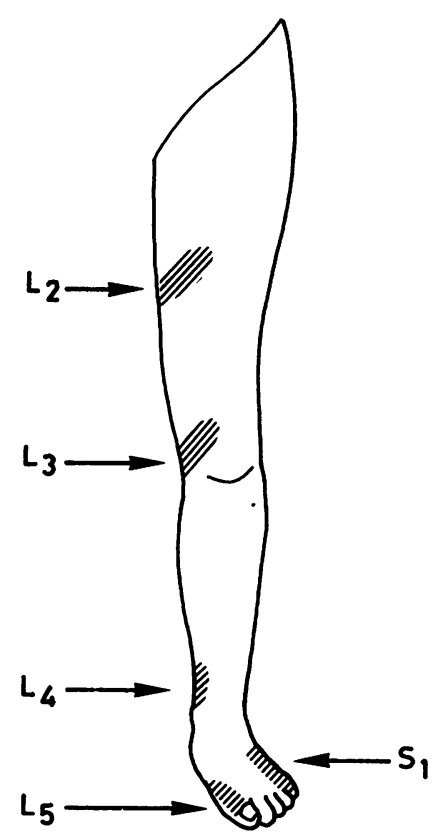

Fig 1 The signature areas of the lumbo-sacral dermatomes are hatched. Dermatomal stimulating electrodes were applied at these sites.
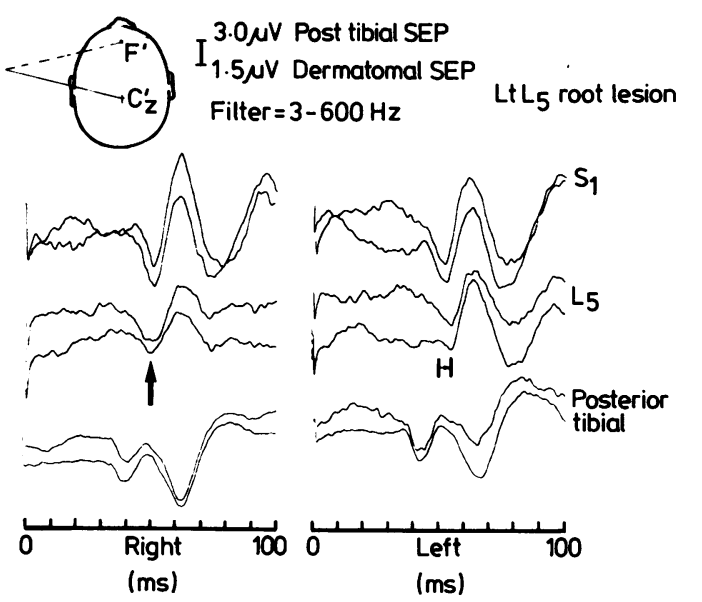

Fig 2 Dermatomal somatosensory evoked potential and tibial nerve SEP are shown from a 23 year old female (case 20) with a surgically proven left $L 5$ root lesion. The response latency from the L5 dermatome was $50.4 \mathrm{~ms}$ on the right and $55.2 \mathrm{~ms}$ on the left. From the SI dermatome the latencies were $51.6 \mathrm{~ms}$ on the right and 52.0 on the left. The side to side difference from $L 5$ was $4.8 \mathrm{~ms}$ and the upper limit of normal is $3.5 \mathrm{~ms}$.

evoked potential findings with the final diagnosis indicates the sensitivity of the test. In 19 of the 21 cases the dermatomal somatosensory evoked potential was abnormal indicating a high sensitivity of the test. It failed to reveal root dysfunction in case 3 . This man had limited straight leg raising but no motor, sensory or reflex signs. Myelography showed a L4/5 prolapsed intervertebral disc which was confirmed at surgery to be compressing the left L5 root. In case 21 there were no clear objective clinical findings except slight limitation of straight leg raising, myelography was normal but a CT scan was interpreted as showing a lateral $\mathrm{L} 5 / \mathrm{S} 1$ prolapsed intervertebral disc. At surgery no compression or disc was seen, root inflammation was reported but no cause was found. In this case the CT scan was, in retrospect, overinterpreted but the dermatomal somatosensory evoked potential had accurately predicted the absence of root compression.

In the other 19 cases the dermatomal somatosensory evoked potential showed an abnormality. In five of these cases no clinical sensory change had been detected despite careful testing. Comparison of the dermatomal somatosensory evoked potential abnormality with the final diagnosis revealed abnormality in the appropriate root or roots and on the expected side in 17/19 cases. Case 1 had a L5/S1 prolapsed intervertebral disc with clinical sensory changes in the left S1 dermatome, however both the dermatomal 
somatosensory evoked potential and the operative finding showed a compressed L5 root, the DSEP predicted the operative finding rather than confirming the clinical changes. Case 10 had a right lateral L5/S1 prolapsed intervertebral disc compressing the $\mathrm{S} 1$ root but clinically there were bilateral L5 motor signs and bilateral S2-S4 sensory signs. The left L5 dermatomal somatosensory evoked potential was abnormal but the operative finding was of a compressed right $\mathrm{S} 1$ root.

In six cases the dermatomal somatosensory evoked potential abnormality was bilateral but only one patient complained of bilateral sciatica and none had bilateral clinical signs. However two had bilateral spondylotic change and three had central prolapsed intervertebral disc so it was possible that the roots were compressed bilaterally.

Both delayed and absent responses were seen; some cases showed both (fig 3). We thought that absent responses may be associated with a more severe clinical deficit but this was not the case. Absent responses were more frequently associated with acute lesions.
Symptoms had been present for a mean of 6.2 months \pm 4.8 in the six cases with absent responses but for 23.2 months \pm 19.2 in those with delayed responses. The difference is statistically significant, $p=0.04$ (Mann-Whitney U test).

Sensory thresholds to electrical stimulation of the dermatomes were determined as part of the procedure. Comparison of the thresholds in $\mathrm{mA}$ with those obtained from normal subjects is given in table 2 . In the painful leg the thresholds were slightly but significantly raised and there was a smaller but not statistically significant rise in the symptom free leg. A significant rise in threshold was also seen from the dermatome giving abnormal potentials regardless of whether the leg was symptom free or not. It was of interest that the threshold from the L5 dermatome was raised even in those patients with a normal dermatomal somatosensory evoked potential again regardless of the presence of symptoms.

Study of table 1 shows that clinically noted sensory loss in the L 5 dermatome was always accompanied by an abnormal dermatomal somatosensory evoked

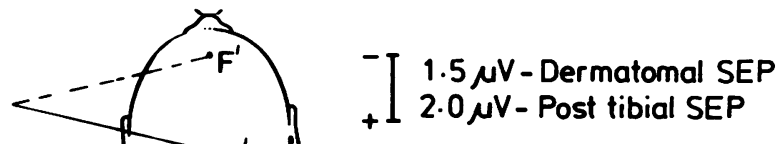

Filter $=3-1500 \mathrm{~Hz}$

$L 3 / 4$ PID + canal stenosis
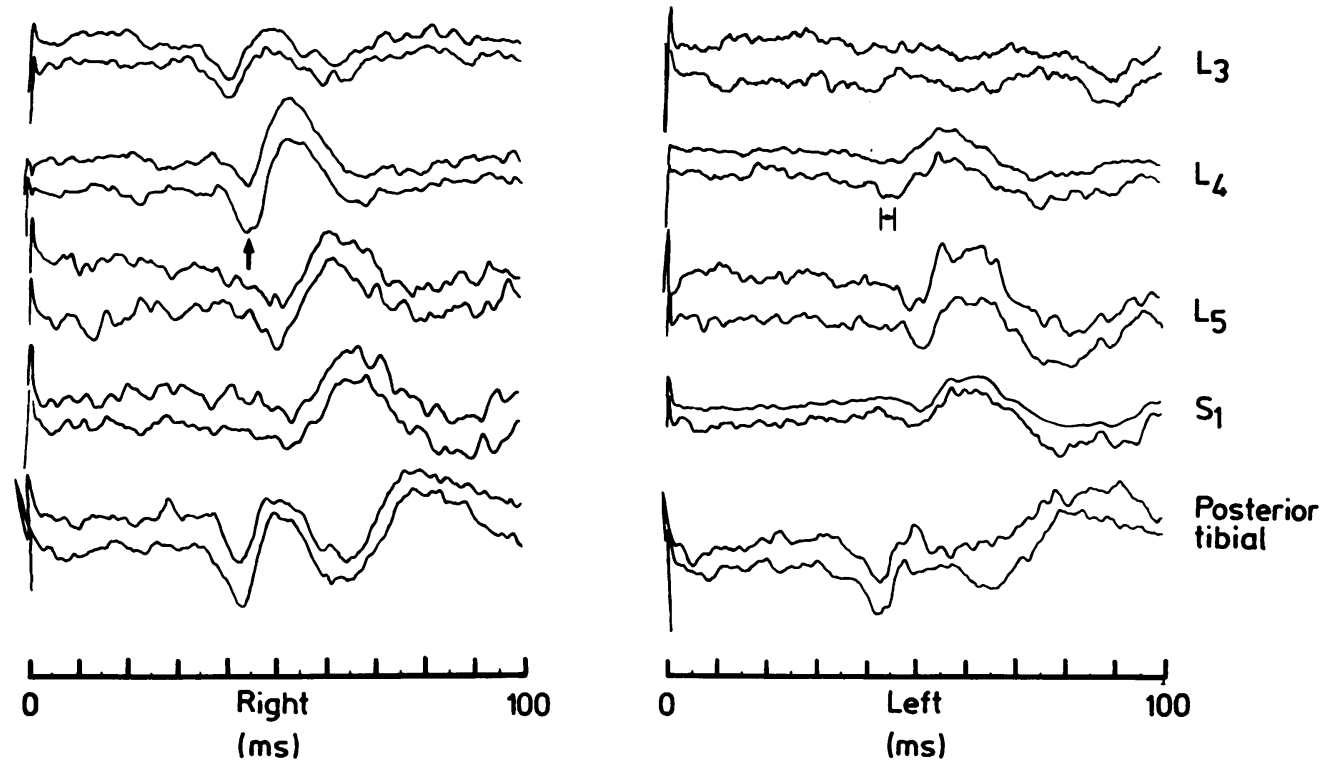

Fig 3 A set of DSEPs from case 18 is shown. Note the absence of response from the left L3 dermatome. The response from $L 4$ was delayed by $2 \cdot 5$ ms compared with the right but the amplitude ratio was just within normal limits at $3 \cdot 9 / 1$. 
Table 2 Sensory Thresholds of L5 and S1 dermatomes to electrical stimulation.

\begin{tabular}{llllll}
\hline Dermatome & Normal & Patients & & \\
\cline { 2 - 6 } & & Painful leg & Other leg & DSEP abnormal & DSEP normal \\
\hline L5 & $4 \cdot 1 \pm 1 \cdot 1(\mathrm{n}=76)$ & $5 \cdot 5 \pm 2 \cdot 9^{*}(\mathrm{n}=17)$ & $4 \cdot 7 \pm 2 \cdot 8(\mathrm{n}=17)$ & $5 \cdot 1 \pm 2 \cdot 7^{*}(\mathrm{n}=19)$ & $5 \cdot 1 \pm 2 \cdot 9^{*}(\mathrm{n}=17)$ \\
S1 & $4 \cdot 2 \pm 1 \cdot 1(\mathrm{n}=76)$ & $4 \cdot 9 \pm 1 \cdot 9^{*}(\mathrm{n}=17)$ & $4 \cdot 6 \pm 1 \cdot 9(\mathrm{n}=17)$ & $5 \cdot 3 \pm 2 \cdot 8^{*}(\mathrm{n}=9)$ & $4 \cdot 5 \pm 1 \cdot 5(\mathrm{n}=27)$ \\
\hline
\end{tabular}

Single stimuli $0.2 \mathrm{mS}$ duration, amplitude in $\mathrm{mA} .{ }^{*}=$ significantly different from normal $(\mathrm{p}=<0.05, t$ test).

potential but the converse was not the case. Sensory abnormalities in the S1 dermatome however were unreliable as predictors of an abnormal dermatomal somatosensory evoked potential. A clinical study has also shown that L5 signs were a more reliable indication of L5 root involvement than S1 symptoms and signs were of predicting S1 root involvement. ${ }^{10}$ The dermatomal somatosensory evoked potentials therefore may be abnormal even though careful sensory testing reveals no abnormality.

SEPs from the posterior tibial nerve were abnormal in only seven patients, all of whom had multiple root involvement, which indicates that stimulation of a nerve trunk is not a sensitive diagnostic test.

\section{Discussion}

\section{Sensitivity of dermatomal somatosensory evoked potential}

The dermatomal somatosensory evoked potential successfully predicted root compression in 19/20 cases; case 21 has been omitted as the surgical findings were inconclusive. In case 3 the dermatomal somatosensory evoked potential gave a false negative result; the reasons for this are speculative but he was the youngest patient and had no objective clinical signs except limited straight leg raising. A small lateral disc was found at surgery. In case 2 the abnormal dermatomal somatosensory evoked potential was found from the asymptomatic leg but the surgeon noted bilateral L5 and S1 compression due to a central disc protrusion. The diagnostic accuracy of the dermatomal somatosensory evoked potential in this group of patients compares favourably with myelography which shows $5-10 \%$ false negatives. ${ }^{11-13}$

Other groups have used dermatomal somatosensory evoked potential for assessing lumbo-sacral radiculopathies ${ }^{14-18}$ with conflicting conclusions about the diagnostic yield. An early study found abnormalities in $92 \%$ of patients ${ }^{14}$ while others ${ }^{15}$ found abnormalities in only $5 / 19$ patients. In the latter study the diagnostic criteria of root compression were so lenient that a low yield does not truly contradict our findings. Previous workers did not have the advantage of a carefully studied control series and an appropriate stimulus strength for cutaneous nerve fibres in the skin was established only recently. ${ }^{3}$ In surgically proven cases of root compression, abnormalities were found in 33/34 patients when the big or little toes were stimulated bilaterally. Rather surprisingly the method depended on detecting an asymmetry of the responses from the two hemispheres. ${ }^{18}$ It is known that a SEP wave can be recorded over both hemispheres from the one leg but the waveform and latency are different on each side. ${ }^{19}$

The dermatomal technique has been applied in a similar manner to cervical radiculopathy. ${ }^{20}$ Poor correlation was noted with the clinical findings, in that half the patients with a radiculopathy had a normal DSEP. Although the test may help in a few cases, its low yield is disappointing (Katifi and Sedgwick unpublished observations). This could be a reflection of greater overlap of dermatomal innervation in the upper as compared with the lower limb. Clinicak experience is that sensory signs in the legs are more reliable than motor but in the arms motor signs are considered more reliable. ${ }^{2122}$

Mixed and sensory nerves have been stimulated in an attempt to detect radiculopathies. ${ }^{152324} \mathrm{We}$ argue that, as each nerve trunk carries fibres which enter the spinal canal by several roots, a monoradiculopathy would be masked by a normal somatosensory evoked potential mediated by impulses in unaffected roots. This was the case in this series where the tibial nerve SEP was abnormal in only $7 / 21$ cases. An interesting series of suspected or myelographically proven radiculopathies showed only $16 / 28(57 \%)$ abnormalities on SEP following cutaneous nerve stimulation. ${ }^{24}$ In view of this it is surprising that another study showed abnormalities of the peroneal nerve SEP in all patients with prolapsed discs. ${ }^{23}$ SEP abnormalities from several nerves were found in a high proportion of patients with spinal stenosis; posterior tibial and peroneal nerves gave abnormal responses in 95 and $90 \%$ respectively while the sensory nerves, sural and saphenous, showed abnormalities in 60 and $12 \%$ of cases. $^{25}$ Spinal stenosis frequently involves several roots and abnormal SEPs from nerve trunks are more likely to be seen.

A valuable extension of SEP studies in spinal stenosis has been the demonstration of reversible deterio- 
ration of the SEP from great and small toes after walking, flexion or extension of the spine in patients complaining of spinal claudication. ${ }^{26}$

\section{Types of abnormality}

In the prolapsed intervertebral disc group of patients, five showed bilaterally abnormal dermatomal somatosensory evoked potentials although only one had bilateral symptoms. The surgical findings in four of these patients confirmed central discs compressing roots bilaterally. In another seven patients, more than one root on one side were shown to be involved and there were discrepancies in the identification of the compressed root between the clinical and surgical findings. Previous studies have noted similar discrepancies. ${ }^{13}$ Abnormal tibial nerve SEPs were seen in only 4/12 patients and all four had involvement of more than one root.

Of the 10 patients with canal stenosis, eight showed involvement of more than one root but the tibial nerve SEP was abnormal in only $3 / 8(38 \%)$. Multiple root involvement is to be expected due to the nature of the underlying pathology of canal stenosis.

\section{Conclusions}

The dermatomal somatosensory evoked potential is a very accurate method of detecting abnormalities in root function and correlates strongly with demonstrable root compressions at surgery. Tibial nerve SEPs detect only a small proportion of patients. The group of patients likely to benefit most from this technique are:

(1) Patients with clinical evidence of root lesion where confirmation of the diagnosis is sought without recourse to invasive procedure, for example patients to be managed conservatively.

(2) Patients with clinical evidence of root lesions where myelography is equivocal or does not explain the symptoms and signs; in this group additional information about the functional status of the nerve roots is invaluable.

(3) Cases where functional overlay predominates or psychogenic sensory loss is suspected.

(4) In spinal stenosis where multiple lesions are usually demonstrable on myelography, knowledge of the roots most severely affected can be a helpful preoperative guide to ensure adequate decompression.

HAK was supported by a grant from the University of Baghdad, Iraq. We thank Mr JG Brice, Mr JS Garfield and Professor JD Pickard, consultant neurosurgeons at the Wessex Neurological Centre for their help in this study.

\section{References}

1 O'Leary JL, Landau WM, Brooks JE. Electroencephalography and electromyography. In: Baker AB, Baker LH, eds. Clinical Neurology, Vol 1. Hagerstown: Harper and Row Inc, 1973:33-34.

2 Leyshon A, Kirwan EO'G, Wynn Parry CB. Electrical studies in the diagnosis of compression of the lumbar root. $J$ Bone Joint Surg 1981;63B:71-5.

3 Katifi HA, Sedgwick EM. Somatosensory evoked potentials from posterior tibial nerve and lumbo-sacral dermatomes. Electroencephalogr Clin Neurophysiol 1986;65:249-59.

4 Sedgwick EM, Katifi HA, Docherty TB, Nicpon K. Dermatomal somatosensory evoked potentials in lumbar disc disease. In: Morocutti C, Rizzo PA, eds. Evoked Potentials: Neurophysiological and Clinical Aspects. Amsterdam: Elsevier, 1985:77-88.

5 Keegan JJ, Garrett FD. The segmental distribution of the cutaneous nerves in the limbs of man. Anat Rec 1948;102:409-37.

6 Wolf JK. Segmental Neurology. Baltimore: University Park Press, 1981.

7 Katifi HA, Nelson RJ, Sedgwick EM. Lumbo-sacral root responses evoked by dermatomal stimulation in man. J Physiol (Lond) 1986;380:60P.

8 Baust W, Ilsen HW, Jorg J. Wambach G. Hohenlokalisation von ruckenmarksquerschnittssyndromen mittels corticaler reizantwortpotentiale. Nervenartz 1972;43:292-304.

9 Arnoldi CC, Brodsky AE, Cauchoix J, et al. Lumbar spinal stenosis and nerve root entrapment. Clin Orthop 1976;115:4-5.

10 Kortelainen P, Puranen J, Koivisto E, Lahde S. Symptoms and signs of sciatica and their relation to localization of the lumbar disc herniation. Spine 1985;10:88-92.

11 Hanson EB, Praestholm J, Fahrenkrug A, Bjerrium J. A clinical trial of amipaque in lumbar myelography. $B r J$ Radiol 1976;49:34-8.

12 MacNab I. Negative disc exploration. J Bone Joint Surg 1971;53A:891-903.

13 Aejmelaeus R, Hilfunen H, Harkonen M, Silverhuth M, VahaTahlo T, Tunturi T. Myelographic versus clinical diagnosis in lumbar disc disease. Acta Orthop Trauma Surg 1984;103:18-25.

14 Scarff TB, Dallmann DE, Bunch WH. Dermatomal somatosensory evoked potentials in the diagnosis of lumbar root entrapment. Surg Forum 1981;32:489-91.

15 Aminoff MJ, Goodin DS, Barbaro NM, Weinstein PR, Rosenblum ML. Dermatomal somatosensory evoked potentials in unilateral lumbosacral radiculopathy. Ann Neurol 1985;17: 171-6.

16 Dvonch V, Scarff T, Bunch WH, et al. Dermatomal somatosensory evoked potentials: Their use in lumbar radiculopathy. Spine 1985;9:291-3.

17 Green J, Gildemeister R, Hazelwood C. Dermatomally stimulated somatosensory evoked potentials in the clinical diagnosis of lumbar disc disease. Clin Electroencephalogr 1983;14: $152-60$.

18 Machida M, Asai T, Sato K, Toriyama S, Yamada T. New approach for diagnosis in herniated lumbosacral disc. Dermatomal somatosensory evoked potentials (DSSEPs). Spine 1986;11:380-4.

19 Beric M, Prevec TS. Distribution of scalp somatosensory potentials evoked by stimulation of the tibial nerve in man. $J$ Neurol Sci 1983;59:205-14.

20 Schramm J. Clinical experience with objective localizafion of the lesion in cervical myelopathy. In: Grote W, Brodk M, Car HE, Klinger M, Nau H-E, eds. Advances in Neurosurgery, vol 8. Berlin: Springer-Verlag, 1980:26-32.

21 Patten D. Neurological Differential Diagnosis. New York: Springer Verlag, 1977.

22 Kimura J. Electrodiagnosis in Diseases of Nerve and Muscle. Principles and Practice. Philadelphia: FA Davis, 1983:449-62.

23 Feinsod M, Blau D, Findler G, Hadani M, Beller AJ. Somato- 
sensory evoked potential to peroneal nerve stimulation in patients with herniated lumbar discs. Neurosurgery 1982;11: 506-11.

24 Eisen A, Hoirch M, Moll A. Evaluation of radiculopathies by segmental stimulation and somatosensory evoked potentials. Can J Neurol Sci 1983;10:178-82.
25 Keim HA, Hadjdu M, Gonzalez EG, Brand L, Balasubramanian E. Somatosensory evoked potentials as an aid in the diagnosis and intraoperative management of spinal stenosis. Spine 1985; 10:338-44.

26 Larson SJ. Somatosensory evoked potentials in lumbar stenosis. Surg Gynecol Obstet 1983;157:191-6. 